\title{
Perceived Motivators and Barriers that Influence Early Career Nurses' Consideration or Pursuit of Doctoral Education
}

Deundra Hearne

Department of Nursing, Southwest Tennessee Community College, 737 Union Ave, Memphis, TN 38103, USA

\section{Abstract}

Background: Currently, nurses with a doctoral education, which qualifies them to fill positions in academia, administration, clinical practice, and research, are in high demand. The development of strategies to ensure a seamless transition to doctoral programs for early career nurses may increase the number of nurses prepared to fill those positions.

Methods: An interview-based qualitative phenomenology design was utilized to explore the motivators and barriers that influence early career nurses' consideration or pursuit of doctoral education. For this study, an early career nurse was defined as a registered nurse who had obtained initial licensure within the past 10 years. Participants included (1) early career nurses who were currently enrolled in a nursing doctoral program and (2) early career nurses who were considering enrolling in a nursing doctoral program within one year. The final sample was comprised of 15 early career nurses.

Results: A qualitative analysis of the data generated from the interviews identified the following primary themes as motivators: (1) personal and professional growth; (2) family, educator, and peer influence; (3) increased ability to serve; and (4) financial gain. The key themes identified as barriers were (1) time constraints, (2) length of study, (3) limited experience, and (4) finances. Primary themes for strategies to alleviate barriers were (1) financial support and (2)planning and shorter length of study.

Conclusion: The motivators and barriers to pursuing doctoral education, as perceived by early career nurses, can be utilized to develop recruitment and retention strategies for nurses seeking doctoral education and create nursing curricula that promote a seamless transition to a doctoral program.

\section{Introduction}

The increasing demand for nurses is causing a simultaneous increase in the demand for doctoral-prepared nurses who are qualified to work in the areas of clinical practice, academia, administration, and research. Within the healthcare workforce, nurses comprise the largest profession, with approximately three million members; however, the number of doctoral-prepared nurses in this group is less than $1 \%$ [1]. In 2010, the Institute of Medicine recommended doubling the number of doctoral-prepared nurses in the United States by 2020 to increase the number of nurses qualified to work in academia and research [2]. Despite a reported increase in enrollment in nursing doctoral programs, the number of nurses who successfully earn a doctoral degree remains low. Between 2010 and 2018, approximately 214,094 nurses enrolled in Doctor of Nursing Practice and Doctor of Philosophy programs, yet only 38,520 completed their program of study and received a degree [3].

The significant gap in nurses' academic careers further perpetuates the shortage of doctoral-prepared nurses. According to Ketefian and Redman [4], the gap in nurses' academic careers has remained unchanged for decades, with the initial gap occurring between the bachelor's and master's degrees, followed by a second gap between the master's and doctoral degrees [4]. Moreover, compared to the educational trajectory of other professions, nurses are, on average, 13 years older by the time they obtain a doctoral degree [5]. This postponement of doctoral education for nurses may significantly impact their ability to create a nurse leader pipeline. Thus, a seamless transition to doctoral education for early career nurses is imperative for preparing the next generation of doctoral-prepared nurses who are needed to maintain the nursing profession's infrastructure.

\section{Statement of the problem}

The theoretical framework used for this study was the SelfDetermination Theory developed by Deci and Ryan. The SelfDetermination Theory is used to study human behavior and provides insight into the need to grow and gain fulfillment [7]. Various factors can influence an individual's motivational drive, which subsequently guides that individual's decision-making process. In this study, the framework was used to study early career nurses' consideration or pursuit of doctoral education in terms of intrinsic motivation, extrinsic motivation, or amotivation.

\section{Literature Review}

Understanding the motivators and barriers to pursue doctoral education for early career nurses is critically important as the demand for nurses continues to grow. Various factors contribute to nurses' intent or desire to pursue doctoral education, which is of particular concern as a lack of academically qualified nurses could negatively impact the profession. A limited number of existing studies have focused on the motivators and barriers to nurses' pursuit of doctoral education, none of which focus on their early transition to doctoral education. The following literature review highlights research that focuses on the nursing shortage, nurse faculty shortage, nursing workforce development, and motivators and barriers to nurses' pursuit of higher education.

\section{Nursing shortage}

The nursing shortage has been an issue of great concern within the United States. Despite a predicted increase in the number of registered nurses between 2014-2030, the distribution of that

"Corresponding Author: Dr. Deundra Hearne, Department of Nursing, Southwest Tennessee Community College, 737 Union Ave, Memphis, TN 38103, USA, Tel: (601) 906-7115; E-mail: dhearne@southwest.tn.edu

Citation: Hearne D (2021) Perceived Motivators and Barriers that Influence Early Career Nurses' Consideration or Pursuit of Doctoral Education. Int J Nurs Clin Pract 8: 334. doi: https://doi.org/10.15344/2394-4978/2021/334

Copyright: (C) 2021 Hearne. This is an open-access article distributed under the terms of the Creative Commons Attribution License, which permits unrestricted use, distribution, and reproduction in any medium, provided the original author and source are credited. 
workforce has created geographical disparities affecting several states [8]. Predictions show that seven states will experience a shortage of nurses by 2030, including New Jersey, South Dakota, South Carolina, Texas, Alaska, and California [8]. The anticipated retirement of one million baby boomer nursing professionals in the next 20 years will also contribute to the need for more nurses [9]. In addition, the aging population, with increasingly complex health conditions requiring chronic care management, will require a nursing workforce with advanced academic qualifications to optimize patient outcomes. The stabilization of the nursing workforce in terms of supply and demand depends on increasing the pipeline of nurses who are academically and experientially qualified to train the next generation. The recruitment and retention of early career nurses in doctoral programs will strengthen the pipeline, extending the number of years that doctoral-prepared nurses can contribute to the profession.

\section{Nurse faculty shortage}

Increasing the number of nurses in the workforce entails that qualified nurse faculty members be available to fill vacant positions in nursing schools throughout the United States. The nurse faculty shortage directly impacts the nursing shortage, as faculty shortages limit student capacity. In 2019, approximately 80,407 qualified applicants were denied admission to baccalaureate and graduate nursing programs, primarily owing to a lack of qualified faculty [10]. Furthermore, the aforementioned looming retirement will increase the faculty shortage. Fang and Kesten [11] reported that, between 2016 and 2025, 44.3\% of faculty members holding research-focused doctorates and $21 \%$ of faculty members holding clinical-focused doctorates would retire. The pool of qualified applicants who will replace the retiring faculty is limited and may present a challenge for nursing programs seeking individuals qualified to teach at the graduate level.

Moreover, various workforce issues contribute to nurses' decisions to quit academia. In their studies, Westphal et al. and Bittner and Bechtel found that the recruitment and retention of qualified nurse faculty members relies on addressing the issues that lead to shortages, such as long work hours, heavy workloads, demanding job duties, stressful work environments, and low salaries $[12,13]$. Also, the aging nurse faculty workforce further worsens the shortage, as the length of time that doctoral-prepared faculty can commit to the profession is limited. According to the American Association of Colleges of Nursing [10], the average age of doctoral-prepared faculty ranges from 50.9 to 62.6 years. Hence, it is essential to recruit and retain early career nurses who are qualified to fill these positions and who have more time to commit to the profession.

\section{Nursing workforce development}

The preparation of a more highly qualified nursing workforce is essential for meeting the demands of a population with increasingly complex medical conditions, advancing nursing science, and improving patient outcomes. The move toward developing a more highly educated nursing workforce has been embraced by many local, state, and national institutions, which have implemented various initiatives to aid the advanced education of nurses. In two studies, Warshawsky et al. and Shen et al. assessed the current educational status and plans for further education of registered nurses in Kansas and Kentucky [14,15]. In Kentucky, $40 \%$ of the participants held a Bachelor of Science in Nursing (BSN) degree, with an additional 17.5\% enrolled in a Bachelor of Science in Nursing program [14]. In Kansas, a $14 \%$ increase in nurses educated at the BSN level was reported.
In addition, $35.7 \%(\mathrm{n}=2,400)$ registered nurses in Kansas planned to pursue advanced nursing education [15]. Registered nurses between the ages of 41 and 60 were less likely to pursue advanced nursing education than those younger than 40 , which further highlights the need for an early transition to doctoral education for nurses [15].

\section{Motivators and barriers}

Various factors can influence a nurse's decision to pursue advanced nursing education. Understanding the motivators and barriers to pursuing advanced nursing education is essential to developing a nursing workforce that is equipped to address the challenges of an ever-changing healthcare system. In their study in a large urban medical facility, Sarver et al. explored the perceived benefits, motivators, and barriers for nurses returning to school for a BSN. Their findings indicated that the perceived benefits were job opportunities and expanded knowledge. Motivators for returning to school were tuition reimbursement and shorter program length. The barriers identified included the time commitment and the expense of books/supplies [16].

Similarly, Romp et al. [17] found that the opportunity for career advancement and personal satisfaction motivated nurses to return to school. Barriers to returning to school for a BSN included financial issues, inflexible workschedules, and time commitments [17]. Likewise, Duffy et al. [18] noted the lack of financial support, the need to juggle multiple commitments, and the lack of monetary compensation for advanced education as barriers and challenges to returning to school for a BSN. The present study focuses on the motivators and barriers that influence early career nurses' consideration or pursuit of doctoral education.

\section{Summary of literature}

Several studies exist that address the issues of nurse faculty shortages, nursing shortages, and the motivators and barriers to nurses pursuing advanced education. The literature provides evidence of the need to prepare academically qualified nurses earlier in their career to assume roles in clinical practice, academia, administration, and research. Despite this evidence, there are no studies regarding the motivations and barriers for early-career nurses to pursue doctoral education. The nurse faculty workforce is aging, with a high number of retirements expected within the coming years. Considering the importance of recruiting early-career nursing professors, it is vitally important to examine the motivators and barriers that influence their consideration or pursuit of doctoral education. The results of this study may aid in the recruitment and retention of nurse prospects who have more time to contribute to the profession through various roles.

\section{Research questions}

The research questions used to guide this study were:

1. What are the perceived motivators that contribute to early-career nurses' consideration or pursuit of doctoral education?

2. What are the perceived barriers that contribute to early-career nurses' consideration or pursuit of doctoral education?

3. What are early-career nurses' perceptions of overcoming barriers to pursuing doctoral education? 


\section{Methodology}

\section{Study design and setting}

This study uses a qualitative phenomenological research method. A qualitative research design was appropriate for understanding the perceived motivators and barriers that influence early-career nurses' consideration or pursuit of doctoral education. The qualitative research design allowed this study to obtain the personal perceptions of the participants regarding motivators and barriers to consider or pursue doctoral education. The study was conducted in the Southern region of the United States.

\section{Participants and sampling}

A snowball sampling method was utilized to recruit participants. The inclusion criteria were "an $\mathrm{RN}$ who obtained initial licensure no more than 10 years before the study and was currently enrolled or considering enrolling in a nursing doctoral program within 1 year." The 10-year timeframe was established based on the average time it may take, depending on the initial degree obtained upon entry into the profession, to complete nursing doctoral studies. The final sample consisted of 15 early career nurses.

\section{Data collection}

Data were collected in individual, semi-structured face-to-face and video-conference interviews. Interviews were conducted over a 30-60 minute timeframe. The semi-structured interviews were conducted using an interview guide, developed by the investigator, comprised of both open and closed-ended questions. The interview guide addressed themes identified in previous research, the purpose of the study, and the related research questions. All interviews were digitally recorded. In addition, written notes were taken during each interview. The data collection and analysis occurred concurrently. Data collection continued until data saturation was met.

\section{Data analysis}

Qualitative content analysis was used for this study. A professional transcriptionist transcribed data collected during the interview process. The interview transcripts and written notes were examined and organized according to the research questions that guided this study. Emerging themes were derived from a careful review of the data. Specifically, recurring ideas and concepts were extracted from the transcripts, coded, and categorized into themes. All data were checked and re-checked against the transcripts and noted in writing to ensure that the data were categorized, coded, and interpreted accurately.

\section{Ethical considerations}

Approval to conduct this study was granted by the Institutional Review Board of William Carey University. Before the interview, participants were provided with an invitation letter and a consent form explaining that participation was voluntary and describing the steps taken to maintain privacy and confidentiality of the data collected. Participants were required to sign a consent form before participating in the face-to-face and video-conference interviews. An alphanumeric code was assigned to each participant before data analysis to maintain confidentiality.

\section{Results}

\section{Demographic characteristics}

Approximately $60 \%(\mathrm{n}=9)$ of participants were considering enrolling in a nursing doctoral program within a year, and $40 \%(n=6)$ of participants were currently enrolled in a nursing doctoral program. The years since initial licensure varied with the majority of participants $(n=10)$ having obtained initial licensure more than five years prior to the study. The highest degree held by the majority of participants was a bachelor's degree $(n=8)$, followed by a master's degree $(n=5)$. Lastly, most participants $(n=14)$ were in the age range of 30-49.

\section{Motivators to pursuing doctoral education}

In this section, the main themes that emerged from the data are highlighted, along with examples that substantiate the themes' development. The participants' responses to the interview questions related to motivators that contribute to early career nurses' consideration or pursuit of doctoral education were overwhelmingly more intrinsically than extrinsically driven. Although some motivating factors aligned with the participants' desires for a reward for accomplishment, the majority of motivators were linked to intrinsic motivators. Four themes emerged to identify the perceived motivators that contribute to early career nurses' consideration or pursuit of doctoral education:

1. Personal and professional growth

2. Family, educator, and peer influence

3. Increased ability to serve

4. Financial gain

Personal and professional growth: The majority of participants provided a response that linked their motivation to consider or pursue doctoral education to personal and professional growth. Participants overwhelmingly used words and phrases such as self-fulfillment, selfmotivated, autonomy, personal goals, and career opportunities. The following responses from participants support the development of this theme as a motivator.

"I would say me; it is something that I am doing for myself, something that I have always wanted to do. So, this was selfmotivated."

"I would have to say that what has motivated me the most is the ability to move forward in my career and the opportunity for better job prospects."

"For my personal growth, this is just something that I did see myself doing. I have a master's as well, but I did not see myself stopping at that particular stage."

Family, educator, and peer influence: Most participants provided responses that linked their motivation to consider or pursue doctoral education to family, a previous educator or a peer. Keywords identified in the responses of several participants that lead to this theme's development include family, educators, children, co-workers, and professors. Participant responses below support the development of this theme as a motivator. 
"Factors that influenced me to pursue my doctorate in nursing would be encouragement from educators in my master's program. My second-semester instructor in my master's program was probably one of the first doctorate nurse educators that I had come across. I am inspired by her to this day. I received a lot of encouragement from her to pursue nursing education at the doctoral level."

"Yes, there was a particular person. When I got into my master's program, she was actually one of my professors, and she recently graduated with a DNP."

"I would say my family. My dad has a doctorate degree in astronomy. My mom, of course, she had a bachelor's degree; but still, they're both educated."

Increased ability to serve: Most participants linked their motivation to consider or pursue doctoral education in nursing to their desire to increase their contribution to their community, patients, and the profession of nursing. The increased ability to serve in these three areas was a great motivator, as shown by their responses. The keywords and phrases identified from participant responses that helped develop this theme include help, educate, community education, improve the profession, and serve the community. The following participant responses support the development of this theme as a motivator.

"Helping people, I would say, is my first motivator. I can help more people as a nurse practitioner prepared at the doctoral level than I can right now as a bachelor's degree nurse. It's just, I always want to help people, so this is just my way of giving back."

"Then, the fact that there is a lot of miseducation within the African American community. That makes me want to have a higher education so that I can educate people within the community about different diseases and how they can be prevented or maintained with treatment options."

"Just to improve the profession of nursing and to bring as much knowledge that I can into the field."

"I feel like a bedside nurse; I am limited in what I can do to help patients. Earning my doctoral degree feel like I would be able to serve the community and my patients better."

Financial gain: Many participants identified financial gain as a motivating factor for considering or pursuing doctoral education in nursing. The keywords and phrases obtained from participant responses that contributed to this theme's development include providing for my family, financial, and money. Listed below are participant responses that support the development of this theme as a motivator.

"I think it'll be a great financial addition because once I'm done, that will definitely take me to another pay grade."

"The first one is money because it's really hard. The only way to get really compensated for the amount of work that we do is to go ahead and pursue my Ph.D. in nursing."

"Another thing is, I would be able to provide for my family in a way that I think would be comfortable for me."

\section{Barriers to pursuing doctoral education}

The majority of participants provided responses that were driven by amotivation, specifically the lack of interest in considering or pursuing doctoral education due to the negative influence of the barriers identified. The participants' responses to the perceived barriers that contribute to early career nurses' consideration or pursuit of doctoral education resulted in four themes:

\section{Finances \\ 2. Length of study \\ 3. Time constraints \\ 4. Limited nursing experience}

Finances: An overwhelming number of participants provided a response related to financial barriers playing a pivotal role in their decision to consider or pursue doctoral education. Key phrases relating to finances as a barrier were identified; these included increased student loan debt, lack of funding, cost, and personal financial responsibilities. The following responses highlight the influence of finances as a barrier to early career nurses' consideration or pursuit of doctoral education.

"I already have a ton of student loans, and I really don't want to add to them. So, there's definitely a big barrier because those student loans can stop you."

"I would have to say that finances would be a major barrier. Along with the financial burden it may place on the family, I may not be able to work as much as I could before the program due to scheduling conflicts. Also, financial issues with financing the degree. Taking out additional student loans can be a barrier when considering going back to school for any degree."

Length of study: Many participants listed the length of the study as a barrier to their decision to consider or pursue doctoral education. The keyword and phrases derived from participant responses used to develop this theme were time and completion time. The following participant responses highlight the developed theme as a barrier to the participants' consideration or pursuit of doctoral education.

"Also, the third barrier, I would say, well, just looking at the time it takes to complete the degree, and you are already working."

"Might be time because depending on which program you decide to go into, some of them can take up to three to four years."

Time constraints: Most participants described time constraints regarding work and family obligations as a barrier to their decision to consider or pursue doctoral education. Key phrases derived from the participants' responses to support this theme's development include time, time constraints, responsibilities, and balance. The following participant responses support the development of the theme of time constraints as a barrier.

"I would have to say that the major barrier to me is time constraints with family and work responsibilities. Balancing it all can be very difficult at times."

"Job requirements and responsibilities, family responsibilities, and monetary responsibilities. I work 35 hours a week as a nurse educator, including clinical and didactic hours." 
Limited nursing experience: Many participants reported limited nursing experience as being either a perceived barrier by others or as a personal barrier that contributed to their decision to consider or pursue doctoral education. Key phrases utilized to develop this theme include more bedside experience, more experienced, and the number of years in nursing. The following responses from participants support the development of this theme as a barrier.

"I would say my number of years in nursing has been a barrier. I think some people look at nine years as not a long time. People who have a doctoral degree for a long time feel that you need to have been a nurse longer. So, I think there is some kind of judgment here about the number of years I have been a nurse."

"I also thought that maybe I needed some more bedside experience before I furthered my education."

\section{Strategies to overcome barriers}

The majority of participant responses highlighted extrinsic motivation as a driving force to overcome the barriers identified. The main concepts that emerged from the participants' responses to their perceptions of overcoming barriers to pursuing doctoral education are:

\section{Financial support and planning}

2. Shorter length of study

Financial support and planning: An overwhelming majority of participants provided responses related to the need for financial support and planning as a strategy to overcome barriers to pursuing doctoral education. Keywords and phrases derived from participant responses that were used to develop this theme include scholarship grants, financial planning, and reimbursement. The following participant responses support the development of this theme as a strategy to overcome barriers to pursuing doctoral education.

"Just the financial planning prior to starting the program and having a plan as far as how to I'm going to pay off that debt after finishing school."

"More workplaces that back education and that are able to reimburse you for education."

"Find more scholarships, more grants, better financial planning."

"Mainly it's for the finances. More resources financially to pursue as for scholarships or grants to help nurses pursue further education."

Shorter length of study: Participants identified the adoption of shorter lengths of study as a strategy to overcoming the barrier of the length of time needed to complete doctoral degrees. Key phrases to include fast track program and shorter length of study were used to support the development of this theme. The following responses support the development of this theme as a strategy to overcome barriers to pursuing doctoral education.

"A fast-track program as far as not having to go two or three years."

"As far as the time that it takes to complete the program, that can be combated by creating more programs with shorter lengths of study."

"As far as time, just making sure that you investigate your program options so that you find a program that fits the time that you want to finish."

\section{Discussion}

This study's principal findings support previous studies that have identified motivators and a continuum of barriers that influence nurses' pursuit of higher education. For example, Sarver et al. identified personal and professional growth as a motivating factor for nurses' consideration or pursuit of doctoral education [16]. In addition, in a study of motivators for nurses pursuing a BSN degree to return to school, Romp et al. identified the opportunity for advancement in leadership roles, personal satisfaction, and the opportunity to obtain another nursing position [17]. Furthermore, the present study's findings reflect previous research on barriers that influence nurses' pursuit of higher education. Dreifuerst et al. and Duffy et al. identified finances as a barrier to pursuing higher education $[19,18]$. Dreifuerst et al. and Squires et al. also highlighted the length of study and time commitment as barriers to pursuing doctoral education $[19,20]$. Finally, Squires et al. identified limited nursing experience as a barrier to pursuing doctoral education, as participants reported that not pursuing a Ph.D. immediately after completing their current program was associated with the desire to work and obtain experience in their new roles [20].

\section{Overarching theme}

Finance was an overarching theme in participant responses to all three research questions in this study. Most participants described finances as an influential component, whether negative or positive, of their decision to consider or pursue doctoral education. Specifically, participants identified financial gain as a motivator for considering or pursuing doctoral education in response to research question one. They also listed finances as a barrier to their consideration or pursuit of doctoral education and the need for financial support and planning as a strategy to alleviate the barriers identified in their responses to questions two and three. The importance of finance has been emphasized in previous studies by Dreifuerst et al., Duffy et al., Robb and Hunker, Romp et al., and Squires et al. [19, 18, 21, $17,20]$. Each study identified finances as a factor that positively or negatively affected nurses' decisions to pursue higher education. The desire for financial gain and support directly aligns with the SelfDetermination Theory's extrinsic motivation, as the individual's behavior is externally controlled [22]. The following figure depicts the overarching themes of motivators and barriers that influence early career nurses' consideration or pursuit of doctoral education.

\section{Implications for nursing education}

The national shortage of nursing faculty will soon reach critical proportions, significantly impacting nursing programs and the future generations of nurses they will educate. Doctoral-prepared nurses are needed to fill faculty roles and serve as directors and deans of nursing programs. Implications for nursing education include the importance of developing programs that promote a seamless transition to doctoral programs for early career nurses.

The results of this study suggest that early career nurses are more inclined to pursue doctoral education when the length of the program aligns with the amount of time they are willing to commit to furthering their education. Thus, nursing programs must provide additional student support services for students pursuing doctoral education. Developing program tracks that limit the amount of time it takes to earn a doctoral degree is one important strategy. Providing flexible program options that help alleviate the stressors 
of balancing work, family, and school responsibilities are another. Deans of nursing and nurse administrators must be aware of the challenges that early career nurses may face in their pursuit of doctoral education, focusing on developing program curriculums that consider their various roles.

In this study, finances were identified as a significant barrier to nurses considering or pursuing doctoral education. Thus, nursing programs should offer funding through scholarships, grants, and stipends to decrease the financial burdens associated with doctoral education. In particular, nursing programs should attempt to provide funding options other than student loans. An increase in student loan debt was identified as a barrier to early career nurses returning to school for doctoral education. Nursing programs should also make tuition more affordable, thereby decreasing the amount of debt accrued by those seeking doctoral education and advocating for doctoral funding support at both the state and federal levels. Finally, nursing programs should emphasize the available financial resources for early career nurses who want to pursue doctoral education. Specifically, programs should more effectively communicate the different options for pursuing doctoral education and the various funding opportunities available.
Participants in this study identified the desire for personal and professional growth as one motivator for pursuing a doctoral degree; therefore, nursing programs should take advantage of this motivator through increased recruitment efforts. Nursing programs should cultivate and nurture relationships with prospective students by increasing outreach efforts. Academic progression can be promoted through outreach to alumni students, which may increase nurses' motivation to consider or pursue doctoral education.

In this study, influence from peers was also identified as a motivation for considering or pursuing doctoral education; therefore, schools of nursing may use alumni to recruit prospective students by sharing their positive experiences in the program. In addition, schools of nursing may use current doctoral students to aid in recruiting prospective students by engaging them in the recruitment process. Schools of nursing may also collaborate with other colleges and schools of nursing to recruit current students and faculty interested in doctoral education. Given the importance of peer influence, schools of nursing may collaborate with healthcare organizations to recruit prospective students by creating organization-specific cohorts or learning communities of peers. Prospective doctoral students are more likely to consider or actively pursue doctoral education when

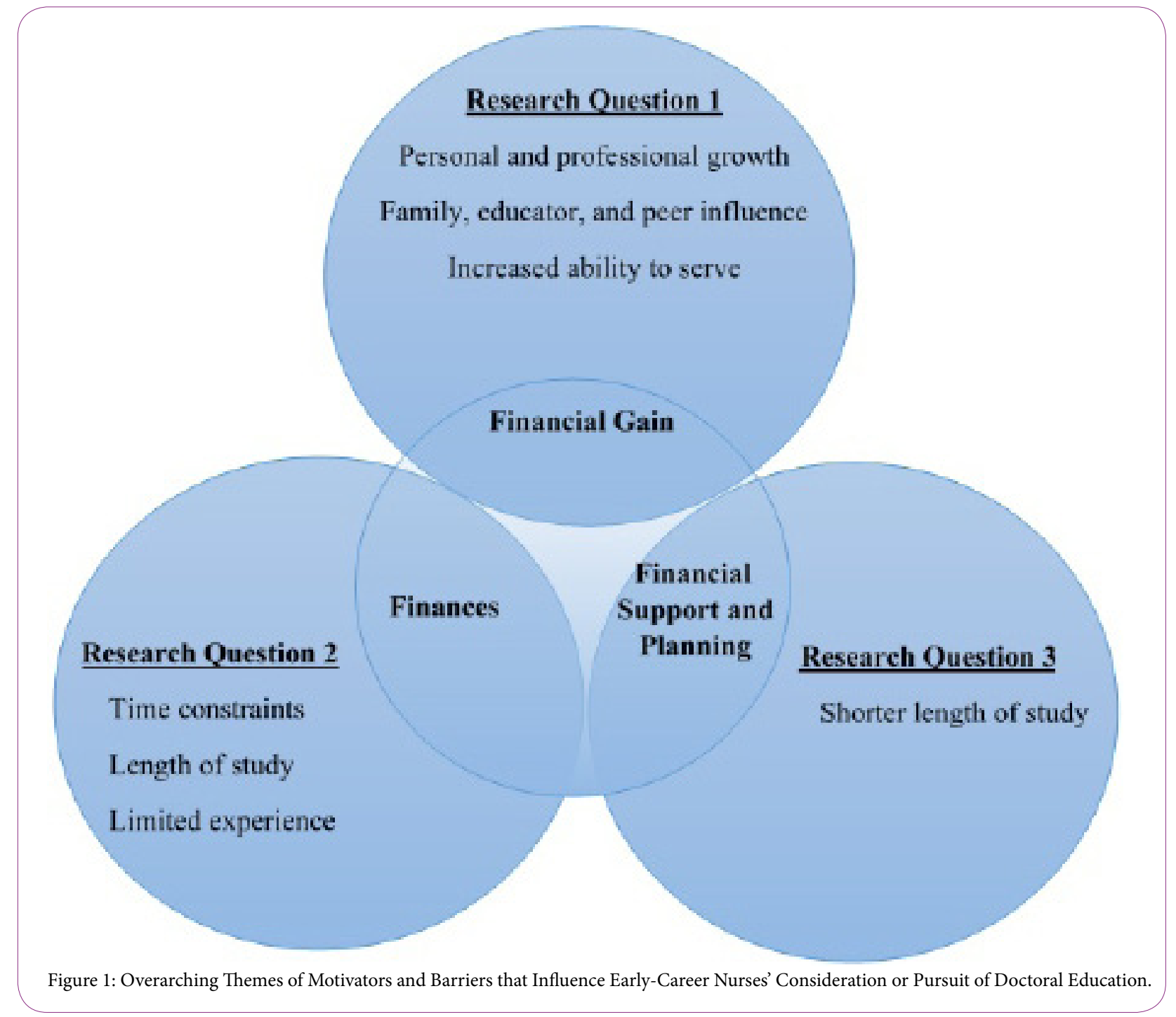


supported by peers. In addition to peer influence, participants in this study reported influence from previous nurse educators as a motivator for considering or pursuing doctoral education. Thus, nurse educators can increase awareness by informing their current students of the doctoral education options available. Nurse educators may also assist in coordinating information sessions highlighting various program options.

\section{Implications for nursing practice}

Research has shown that higher levels of education among nurses leads to improved patient outcomes, an outcome identified as a motivator for the participants in this study. Specifically, the results of this study suggest that early career nurses aspire to pursue doctoral education to increase their ability to serve the profession, serve patients, and educate the community. Correspondingly, the American Association of Colleges of Nursing's (AACN) 2004 position statement on the practice doctorate in nursing recommends support for al graduates' education at the highest level of nursing practice for all practice-focused doctoral programs.

Participants in this study identified financial gain as a motivator to consider or pursue doctoral education. Therefore, healthcare organizations should seek to provide monetary compensation for nurses who obtain higher education. In addition, financial compensation based on degree level is recommended. Participants also identified finances as a barrier to pursuing doctoral education. Implications for nursing practice include the need for clinical practice agencies to offer tuition assistance programs for clinicians seeking doctoral education. Financial assistance and support through tuition reimbursement or fee waiver programs may help alleviate the barriers faced by nurses seeking doctoral education with a clinical practice focus.

Participants in this study identified time constraints as an additional barrier to considering or pursuing doctoral education Therefore, healthcare organizations must alleviate stressors associated with balancing work, family, and school responsibilities. Implications for nursing practice include collaboration among healthcare organizations and academic institutions to transition to doctoral education seamlessly. Collaboration between healthcare organizations and academic institutions may lead to the development of flexible programs conducive to nurses pursuing doctoral education while working. Healthcare organizations should provide flexible scheduling for those seeking to advance their education. Providing educational leave for nurses who are pursuing higher education is also recommended as a strategy.

\section{Implications for nursing policy}

Nurses are at the center of the healthcare system and play a vital role in developing and implementing nursing policies that support best practice environments. Participants identified an improved ability to serve as a motivator to consider or pursue doctoral education. Therefore, implementing strategies to enable early career nurses to serve the profession by contributing to nursing policy development is recommended. Implications for nursing policy include providing nurses with resources for obtaining the advanced knowledge necessary to practice at the highest standard. Doctoral-prepared early career nurses with clinical practice, academic, or research focus are equipped to contribute to the successful development of healthcare policies that may positively impact patient outcomes and, ultimately, the future of nursing.
Additional implications for nursing policy include the need to develop, implement, and sustain federal programs to aid in funding higher education for early career nurses. Federally funded grant programs should be provided to nursing schools seeking to educate the next generation of nurses to fill positions in clinical practice, academia, and research. In addition, federally funded programs aimed at providing student loan relief for early career nurses who obtain doctoral degrees and fill vacant positions critical to the profession's sustainability should be provided.

\section{Study limitations and future research}

The present study qualitatively explored the motivators and barriers influencing early career nurses in the United States' Southern region to consider or pursue doctoral education. However, the scope of the qualitative research design, sampling size, and geographical considerations limit the findings' generalizability. The development of a quantitative study utilizing the themes that emerged from this study would provide greater insight into the topic and increase generalizability. Further research on early career nurses' lived experiences during their pursuit of doctoral education may help identify challenges and develop strategies to alleviate difficulties in completing their education.

\section{Conclusion and Recommendations}

The results of this study highlight a continuum of barriers to nurses pursuing doctoral education. This continuum is concerning as these barriers further contribute to the lack of nurses prepared at the doctoral level to fill positions in academia, clinical practice, and research. The findings highlight the need to provide financial support in the form of grants, scholarships, and other forms of tuition assistance. Despite the barriers, most early career nurses reported an intrinsically driven desire to further their education as a means of self-fulfillment.

Recommendations include developing doctoral curricula that provide a seamless transition for early career nurses pursuing doctoral education. The length of study for nursing doctoral programs must be strategically reduced to increase the number of early career nurses pursuing doctoral education. Nursing programs must consider nurses' various roles during their doctoral education and create a curriculum that is conducive to working professionals balancing multiple responsibilities. Financial assistance must be provided that may decrease or eliminate the cost associated with pursuing doctoral education, as the reluctance to accumulate additional student loan debt serves as a significant barrier to early career nurses pursuing doctoral education. Early career nurses prepared at the doctoral level, with increased career longevity, can substantially contribute to the nursing profession.

\section{Competing Interests}

The author declare that there is no competing interests regarding the publication of this article.

\section{References}

1. Robert Wood Johnson Foundation (2013) RWJF announces $\$ 20$ million grant to support nurse PhD scientists.

2. Institute of Medicine (2010) The future of nursing: Leading change, advancing health. Washington, DC: National Academy Press.

3. Campaign for Action (2019) Number of people receiving nursing doctoral degrees annually. 
4. Ketefian S, Redman RW (2015) A critical examination of developments in nursing doctoral education in the United States. Rev Lat Am Enfermagem 23: 363-371.

5. Robert Wood Johnson Foundation (2013) Wanted: Young nurse faculty.

6. Auerbach DI, Buerhaus PI, Staiger DO (2015) Will the RN workforce weather the retirement of the baby boomers? Med Care 53: 1-7.

7. Ryan RM, Deci EL (2000) Intrinsic and extrinsic motivations: Classic definitions and new directions. Contemp Educ Psychol 25: 54-67.

8. Health Resources and Services Administration (2017) Supply and demand projections of the nursing workforce: 2014-2030.

9. Carnevale AP, SmithN, Gulish A (2015) Nursing supply and demand through 2020.

10. American Association of Colleges of Nursing (2020) AACN fact sheet Nursing faculty shortage.

11. Fang D, Kesten K (2017) Retirements and succession of nursing faculty in 2016-2025. Nursing Outlook 65: 633-642.

12. Westphal J, Marnocha S, Chapin T (2015) A pilot study to explore nurse educator workforce issues. Nurs Educ Perspect 37: 171-173.

13. Bittner NP, Bechtel CF (2017) Identifying and describing nurse faculty workload issues. Nurs Educ Perspect 38: 171-176.

14. Warshawsky NE, Brandford A, Barnum N, Westneat S (2015) Achieving 80\% BSN by 2020: Lessons learned from Kentucky's registered nurses. J Nurs Adm 45: 449-456.

15. Shen Q, Peltzer J, Teel C, Pierce J (2015) The initiative to move toward a more highly educated nursing workforce: Findings from the Kansas registered nurse workforce survey. J Prof Nurs 31: 452-463.

16. Sarver W, Cichra N, Kline M (2015) Perceived benefits, motivators, and barriers to advancing nurse education: Removing barriers to improve success. Nurs Educ Perspect 36: 153-156.

17. Romp CR, Kiehl EM, Bickett A, Bledsoe SF, Brown DS, et al. (2014) Motivators and barriers to returning to school: RN to BSN. J Nurses Prof Dev 30: 83-86.

18. Duffy MT, Friesen MA, Speroni KG, Swengros D, Shanks LA, et al. (2014) SDC 1.

19. Dreifuerst KT, McNelis AM, Weaver MT, Broome ME, Draucker CB, et al (2016) Exploring the pursuit of doctoral education by nurses seeking or intending to stay in faculty role. J Prof Nurs 32: 202-212.

20. Squires A, Kovner C, Faridaben F, Chyun D (2014) Assessing nursing student intent for PhD study. Nurse Educ Today 34: 1405-1410.

21. Robb M, Hunker DF (2018) Identifying motivational factors for enrolling in a doctor of nursing practice program. J Nurs Educ 57: 680-683.

22. Ryan RM, Deci EL (2000) Self-determination theory and the facilitation of intrinsic motivation, social development, and well-being. Am Psychol 55: 68-78. 